\title{
Principal component analysis and quantitative image analysis to predict effects of toxics in anaerobic granular sludge
}

\author{
J.C. Costa, M.M. Alves, E.C. Ferreira * \\ IBB - Institute for Biotechnology and Bioengineering, Centre of Biological Engineering, University of Minho, Campus de Gualtar, 4710-057 Braga, Portugal
}

\section{A R T I C L E I N F O}

\section{Article history:}

Received 1 July 2008

Received in revised form 28 August 2008

Accepted 3 September 2008

Available online 19 October 2008

\section{Keywords:}

Detergent

Principal component analysis

Quantitative image analysis

Solvent

Toxic shock load

\begin{abstract}
A B S T R A C T
Principal component analysis (PCA) was applied to datasets gathering morphological, physiological and reactor performance information, from three toxic shock loads (SL1 - $1.6 \mathrm{mg}_{\text {detergent }} / \mathrm{L}$; SL2 - 3.1 $\mathrm{mg}_{\text {detergent }} / \mathrm{L}$; SL3 - $40 \mathrm{mg}_{\text {solvent }} / \mathrm{L}$ ) applied in an expanded granular sludge bed (EGSB) reactor. The PCA allowed the visualization of the main effects caused by the toxics, by clustering the samples according to its operational phase, exposure or recovery. The aim was to investigate the variables or group of variables that mostly contribute for the early detection of operational problems. The morphological parameters showed to be sensitive enough to detect the operational problems even before the COD removal efficiency decreased. As observed by the high loadings in the plane defined by the first and second principal components. PCA defined a new latent variable $t[1]$, gathering the most relevant variability in dataset, that showed an immediate variation after the toxics were fed to the reactors. $t[1]$ varied $262 \%, 254 \%$ and $80 \%$, respectively, in SL1, SL2 and SL3. The high loadings/weights of the morphological parameters associated with this new variable express its influence in shock load monitoring and control, and consequently in operational problems recognition.
\end{abstract}

(c) 2008 Elsevier Ltd. All rights reserved.

\section{Introduction}

In the last decades, the anaerobic wastewater treatment technology emerged to beat against the well established activated sludge process for wastewater treatment. The development of high-rate reactors, using anaerobic granular sludge, was the key feature that allowed for a great increase in the use of anaerobic technology for the treatment of a growing variety of industrial wastewaters (Lettinga, 1995). Uncoupling the hydraulic retention time from the solids retention time allows the application of high organic loading rates, making possible the use of compact and economical wastewater treatment plants. Although all the advantages associated with this technology, due to its highly specialized character, the microorganisms involved in the process are very sensitive to disturbances of the normal operational conditions. A frequent problem is the contamination by toxic compounds. Due to the slow start-up of anaerobic wastewater treatment processes this problems can be transformed in several weeks to several months necessary for the reactor to recover if the appropriate measures/actions are not taken in time. Therefore, stable operation of high-rate anaerobic reactors is an essential but difficult task because of the complicated nature of the anaerobic process itself. Monitoring and control are therefore extremely important to im-

\footnotetext{
* Corresponding author. Tel.: +351 253 604400; fax: +351 253678986.

E-mail address: ecferreira@deb.uminho.pt (E.C. Ferreira).
}

prove process robustness by detecting disturbances leading to abnormal process operation. In this context, identification of process variables potentially useful as early alert detectors of instability has major relevance.

Industrial wastewaters that are treated by anaerobic digestion processes are frequently affected by temporary toxic exposures. Detergents (Gavala and Ahring, 2002) and solvents (Enright et al., 2005), from cleaning stages, are some of that compounds that can deteriorate the performance of those processes.

An important factor for the efficient operation of anaerobic processes, extensively studied in the last decade, is the recognition of parameters that could be used for monitoring and control of the process. Parameters in the solid phase are not often used for automatic monitoring and control since they usually need manual operations, and are usually qualitative and inaccurate. Therefore, so far, parameters used for control have been limited to indicators of the liquid and the gaseous phases, such as $\mathrm{pH}$, volatile fatty acids (VFA), alkalinity, COD concentrations, carbon dioxide, methane and hydrogen contents in the biogas as well as biogas production (Van Lier et al., 2001). In this framework, quantitative image analysis techniques emerge as a promising tool to overcome these difficulties, providing quantitative parameters of the solid phase dynamics. Image analysis has become a very important tool with a large field of applications in study of biomass morphology, due to its ability to remove the subjectiveness of human analysis, the possibility to extract quantitative data and avoid tedious and highly time-consuming tasks to human researchers (Amaral, 2003). 
Because the experimental approach of integrating reactor performance, physiological and morphological data may produce correlated and redundant data, a statistical instrument should be applied in order to extract the essential information for process monitoring and fault detection applications. Often, important information lies not in any individual variable but in how the variables change with respect to one another, i.e., how they co-vary (Wise and Gallagher, 1996). Data reduction and interpretation can be approached through the application of multivariate statistical methods, such as principal components analysis (PCA). This method allows identifying patterns in data, and expressing them in order to highlight their similarities and differences. PCA is a projection method for analyze data and reduce it from an $n$-dimensional space to few latent/hidden variables (Lee et al., 2006), while keeping information on its variability. It has been successfully applied to the monitoring of industrial processes (Li et al., 2000; MacGregor and Koutodi, 1995) and wastewater treatment processes (Lee et al., 2004; Lee and Vanrolleghem, 2004; Rosen, 2001). Since patterns in data can be hard to find in data of high dimension, where graphical representation is not available, the possibility of grouping the variability in few variables is an important step to visualize and consequently analyze the information. PCA is a very useful tool to group samples according to its characteristics and detection of the variables with higher influence in that grouping as stated in several works (Zbytniewski and Buszewski, 2005; Abouelwafa et al., 2008; Fuentes et al., 2008; Gil et al., 2008).

Previously, three toxic shock loads were applied to lab-scale expanded granular sludge bed (EGSB) reactors (Costa et al., 2007). The corresponding effects were monitored by quantitative image analysis, specific methanogenic activity tests and reactor performance. In the present study, the multivariate statistical tool PCA was applied in order to highlight patterns, groups, trends and outliers in the data. In addition, it was employed to identify the variables that mostly reflect the shock load effects, and respective operational changes/problems recognition.

\section{Methods}

\subsection{Toxics characterization}

The contaminants tested consisted in industrials detergent and solvent used as cleaning agents. The detergent presents a relative density of 1.04 (at $\left.20^{\circ} \mathrm{C}\right), \mathrm{pH}\left(81 \%\right.$ solution at $\left.20^{\circ} \mathrm{C}\right)$ of 11.4 , and chemical oxygen demand (COD) of $98 \mathrm{~g} / \mathrm{L}$. It is composed by glycol ether (1-10\%), anionic surfactant (1-10\%), performance additives $(1-10 \%)$, dyes $(<1 \%)$, and water $(>60 \%)$. The solvent is a mixture of saturated aliphatic and alicyclic C7 to C12 hydrocarbons with a maximum content of $25 \%$ of $\mathrm{C} 7$ to $\mathrm{C} 12$ alkyl aromatic hydrocarbons. It presents a specific mass $\left(15^{\circ} \mathrm{C}\right)$ of about $0.785 \mathrm{~kg} / \mathrm{m}^{3}$.

\subsection{Operational conditions}

Three shock loads were applied to expanded granular sludge bed (EGSB) reactors. In the two first shock loads, SL1 and SL2, a detergent was fed to the reactor with a concentration of 1.6 and $3.1 \mathrm{mg} / \mathrm{L}$, respectively (Costa et al., 2007). In the third shock load (SL3) $40 \mathrm{mg} / \mathrm{L}$ of solvent was fed to the EGSB reactor (Table 1).

The EGSB reactor consisted in a Plexiglas column with a height of $1.95 \mathrm{~m}$ and internal diameter of $21 \mathrm{~mm}$. The working volume was $1.15 \mathrm{~L}$, and the superficial velocity was $4.0 \pm 0.1 \mathrm{~m} / \mathrm{h}$. Temperature was kept at $37 \pm 1{ }^{\circ} \mathrm{C}$ by means of an external jacket for water circulation.

Anaerobic granular sludge was collected in a full-scale EGSB reactor from a brewery to inoculate and a lab-scale EGSB reactor treating a synthetic effluent, with ethanol as sole organic carbon
Table 1

Shock loads conditions

\begin{tabular}{|c|c|c|c|}
\hline Shock load & SL1 & SL2 & SL3 \\
\hline VSS $(g / L)$ & 22.0 & 34.0 & 26.5 \\
\hline $\mathrm{SAA}\left(\mathrm{mLCH}_{4 @ S T P} / \mathrm{gVSS} \mathrm{d}\right)$ & $150 \pm 22$ & $141 \pm 8$ & $212 \pm 27$ \\
\hline 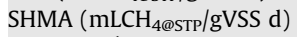 & $833 \pm 136$ & $1028 \pm 103$ & $910 \pm 85$ \\
\hline $\operatorname{LfA}\left(\mathrm{mm}^{-1}\right)$ & 30 & 18 & 24 \\
\hline TL/VSS (m/g $\mathrm{gss})$ & 1585 & 1238 & 1800 \\
\hline VSS/TA $\left(\mathrm{g} / \mathrm{m}^{2}\right)$ & 19 & 27 & 13 \\
\hline vsed $(\mathrm{m} / \mathrm{h})$ & $30 \pm 9$ & $31 \pm 10$ & $26 \pm 14$ \\
\hline HRT $(\mathrm{h})$ & 7.8 & 7.5 & 8.0 \\
\hline Ethanol $\left(\mathrm{g}_{\mathrm{COD}} / \mathrm{L}\right)$ & 1.5 & 1.5 & 1.5 \\
\hline Toxic & Detergent & Detergent & Solvent \\
\hline Concentration (mg/L) & 1.6 & 3.1 & 40 \\
\hline Exposure phase $(\mathrm{h})$ & 56 & 222 & 222 \\
\hline Recovery phase (days) & 14 & 12 & 7 \\
\hline
\end{tabular}

source. Afterwards, $400 \mathrm{~mL}$ of the lab-scale reactor biomass was used as the inoculum of the EGSB reactors used in these experiments. The inoculum was characterized in terms of morphology, specific acetoclastic activity (SAA) and specific hydrogenotrophic methanogenic activity (SHMA), settling velocity (vsed), and volatile suspended solids (VSS) (Table 1). Ethanol was fed at a concentration of $1.5 \mathrm{~g}_{\mathrm{COD}} / \mathrm{L}$. Sodium bicarbonate was added as the alkalinity source $(3 \mathrm{~g} / \mathrm{L})$ and macro- and micronutrients were added according to Zehnder et al. (1980).

\subsection{Datasets}

Variables summarizing the morphological, physiological and performance data obtained during the experiments were grouped to create the datasets used to perform the PCA (Table 2). Four datasets were created, one for each disturbance, and one integrating the data from all shock loads.

\subsection{Principal components analysis}

PCA aims at finding and interpreting hidden complex, and possibly causally determined, relationships between features in a dataset. Correlating features are converted to the so-called factors which are themselves noncorrelated (Einax et al., 1997). PCA modeling, i.e., the approximation of a matrix by a model, defined by

Table 2

Variables included in dataset, summarizing the changes occurred during shock loads

\begin{tabular}{|c|c|}
\hline Variable & Name \\
\hline \multicolumn{2}{|c|}{ Reactor performance data: } \\
\hline OLR & Organic loading rate \\
\hline Cdet & Detergent concentration (datasets 1 and 2) \\
\hline Csol & Solvent concentration (dataset 3 ) \\
\hline Tox & Toxic concentration (detergent or solvent) (dataset 4) \\
\hline Eff & Chemical oxygen demand (COD) removal efficiency \\
\hline $\mathrm{pH}$ & $\mathrm{pH}$ \\
\hline VSS & Effluent volatile suspended solids \\
\hline \multicolumn{2}{|c|}{ Physiological data: } \\
\hline SAA & Specific acetoclastic activity \\
\hline SHMA & Specific hydrogenotrophic methanogenic activity \\
\hline \multicolumn{2}{|c|}{ Morphological data: } \\
\hline LfA & Total filaments length per total aggregates projected area \\
\hline TL/VSS & Total filaments length per volatile suspended solids \\
\hline VSS/TA & VSS per total aggregates projected area (apparent granules density) \\
\hline$>1$ & $\begin{array}{l}\text { Percentage of aggregates projected area with equivalent diameter } \\
\left(D_{\text {eq }}\right) \geqslant 1 \mathrm{~mm}\end{array}$ \\
\hline$>0.1$ & $\begin{array}{l}\text { Percentage of aggregates projected area within the range } 0.1 \leqslant D_{\text {eq }} \\
(\mathrm{mm})<1\end{array}$ \\
\hline$<0.1$ & Percentage of aggregates projected area with $D_{\mathrm{eq}}<0.1 \mathrm{~mm}$ \\
\hline vsed & Settling velocity \\
\hline
\end{tabular}


variables and a relatively small number of outer vector products, shows the correlation structure of a data matrix $X$, approximating it by a matrix product of lower dimension $\left(T \times P^{\prime}\right)$, called the principal components (PC), plus a matrix of residuals $(E)$ :

$X=1 \times \bar{x}^{\prime}+T \times P^{\prime}+E$

where, the term $1 \times \bar{x}^{\prime}$ represents the variable averages. The second term, the matrix product $T \times P^{\prime}$, models the structure and the third term, $E$, contains the deviations between the original values and the projections, i.e., the noise. $T$ is a matrix of scores that summarizes the $X$-variables (scores), and $P$ is a matrix of loadings showing the influence of the variables on each score. Geometrically, it corresponds to fitting a line, plane, or hyper plane to the data in the multidimensional space, with the variables as axes. The scaling of the variables specifies the length of the axes of this space.

SIMCA-P (Umetrics $A B$ ) software package was used to perform the PCA. The first step of the analysis consists in the pre-treatment of data by standardization of the variables, i.e., guarantee that each individual variable has about the same range, avoiding that some variables would be more important than others because of scale effects. During this work each variable was autoscaled by

$Z_{i j}=\frac{x_{i j}-\bar{x}_{i j}}{s_{j}}$

where, $x_{i j}$ is the value of the variable $j$ in the sample $i, \bar{x}_{j}$ and $s_{j}$ are the mean and the standard deviation of the variable $j$, respectively, and, $z_{i j}$ is the autoscaled value of $x_{i j}$. At the end of this standardization, each variable has mean zero and unit standard deviation.

Subsequently, the software iteratively computes one PC at a time, comprising a score vector $t_{\mathrm{a}}$ and a loading vector $p_{\mathrm{a}}$. The score vectors contain information on how the samples relate to each other. Otherwise, the loading vectors define the reduced dimension space and contain information on how the variables relate to each other. Usually, few PC ( 2 or 3 ) can express most of the variability in the dataset when there is a high degree of correlation among data.

The criterion used to determine the model dimensionality (number of significant components) was cross validation (CV). Part of data is kept out of the model development, and then are predicted by the model and compared with the actual values. The prediction error sum of squares (PRESS) is the squared differences between observed and predicted values for the data kept out of the model fitting. This procedure is repeated several times until data element has been kept out once and only once. Therefore, the final PRESS has contributions from all data. For every dimension, SIMCA computes the overall PRESS/SS, where SS is the residual sum of squares of the previous dimension. A component is considered significant if PRESS/SS is statistically smaller than 1.0.

\section{Results and discussion}

\subsection{Recognition of shock load effects}

Apply a chemometric technique such as PCA is advantageous when an effective reduction of the multi dimensional space into few components is accomplished, while keeping the variability of

Table 3

Total datasets variability contained in the firsts principal components

\begin{tabular}{lccc}
\hline PC & SL1 (\%) & SL2 (\%) & SL3 (\%) \\
\hline 1 & 65.5 & 46.3 & 38.1 \\
2 & 14.3 & 23.9 & 23.8 \\
3 & 9.6 & 14.6 & 12.0 \\
4 & 7.5 & 7.0 & 11.2 \\
Cumulative & 96.9 & 91.7 & 85.1 \\
\hline
\end{tabular}

the dataset. In this study, three PC in detergent shock loads (SL1 and SL2) and four PC in solvent shock load (SL3) gathered more than $80 \%$ of the total variability in the datasets (Table 3 ).

PCA is very useful in grouping samples according to sludge characteristics (Abouelwafa et al., 2008). In the score plots of the first and second PCs, t[1] vs. t[2] (Fig. 1a, c and e) is observed that the PCA grouped samples according to its operational phase. A cluster encompassing the observations obtained during exposure phase is visible in each score plot. Besides, is clearly observed that a deviation occurred immediately after the shock loads were applied. The inoculum sample, which emerge as an isolated observation, is located far from the first observation during exposure time (see line in Fig. 1a, c and e).

The influence that each measured variable had in each score, is given by its loadings, i.e., weighted variables, and respective loading maps (Fig. 1b, d and e). It allows decide which variables are most important for the differences observed between the samples. The interpretation of the loadings is essentially done by looking at what variables have the higher coefficients (positive or negative) on a certain PC. Coupled visualization of score and loading plots (Fig. 1) allows for the detection of the main effects/problems occurred during the shock loads. For example, the main effects caused by SL1 were detected in the morphological parameters. The introduction of the toxic compound in the feeding caused an increase in LfA and TL/VSS parameters and decrease in VSS/TA (Fig. 1b). These results suggest changes at the granules microstructure level with release of filaments and decrease of apparent density (VSS/TA). However, during reactors operation, the COD removal efficiency remained unaffected (Costa et al., 2007).

Increasing the detergent concentration (SL2) caused an immediate decrease in specific acetoclastic activity (SAA) and VSS/TA (Costa et al., 2007). Analyzing the Fig. 1c is observed that sample 0 (inoculum) is situated in the top of the graph with the higher score in PC2. Simultaneously, the variables with higher influence in PC2, were SAA and VSS/TA (Fig. 1d, $p[2]$ ). PC1 distinguished samples during exposure time (positive scores) from samples during recovery phase/inoculum (negative scores) (Fig. 1c, $t[1])$. Once more, the morphological parameters LfA and $>1$, were the most sensitive to recognize the shock load (Fig. 1d, $p[1]$ ).

In SL3, the isolation of exposure phase samples is not so effective using only the first PC, since it gathered just $38.1 \%$ of the dataset variability (Fig. 1e, $t[1]$ ). However, analyzing PC1-PC2 plane, a cluster encompassing these samples is visible. The granules size distribution $(<0.1,>0.1$ and $>1)$ show high loadings in PC2 (Fig. 1f, $p[2]$ ). Simultaneously, vsed and VSS present high loadings in PC1 (Fig. 1f, $p[1]$ ). Therefore, it is possible to say that these were the variables with higher influence in clustering the samples. The reactor performance was constant during the exposure phase with COD removal efficiency $>90 \%$. However, in the last hours of exposure the biogas production and methane content start to decrease. Afterwards, the efficiency decreased, and $70 \mathrm{~h}$ after the shock load stopped, reached its minimum (<35\%). Thus, although the reactor performance deteriorates only in the last hours of the exposure phase, a change in the macrostructure of granules was observed immediately when the shock load was applied. In fact, the \% of aggregates projected area with equivalent diameter $\left(D_{\mathrm{eq}}\right) \geqslant 1 \mathrm{~mm}$ decreased from 81 to 53, and the \% of aggregates projected area with $0.1 \leqslant D_{\text {eq }}(\mathrm{mm})<1$ increased from $18 \%$ to $46 \%$, indicator of granules fragmentation and consequent washout (more than $330 \%$ increase in the effluent VSS).

In the last decade, a vast number of methods to monitoring and/or control of wastewater anaerobic digestion processes have been proposed with different parameters as indicators of operational problems (Garcia et al., 2007; Lardon et al., 2005). However, the integration of morphological parameters has not yet been studied, mainly because expeditiously and quantitative information is 

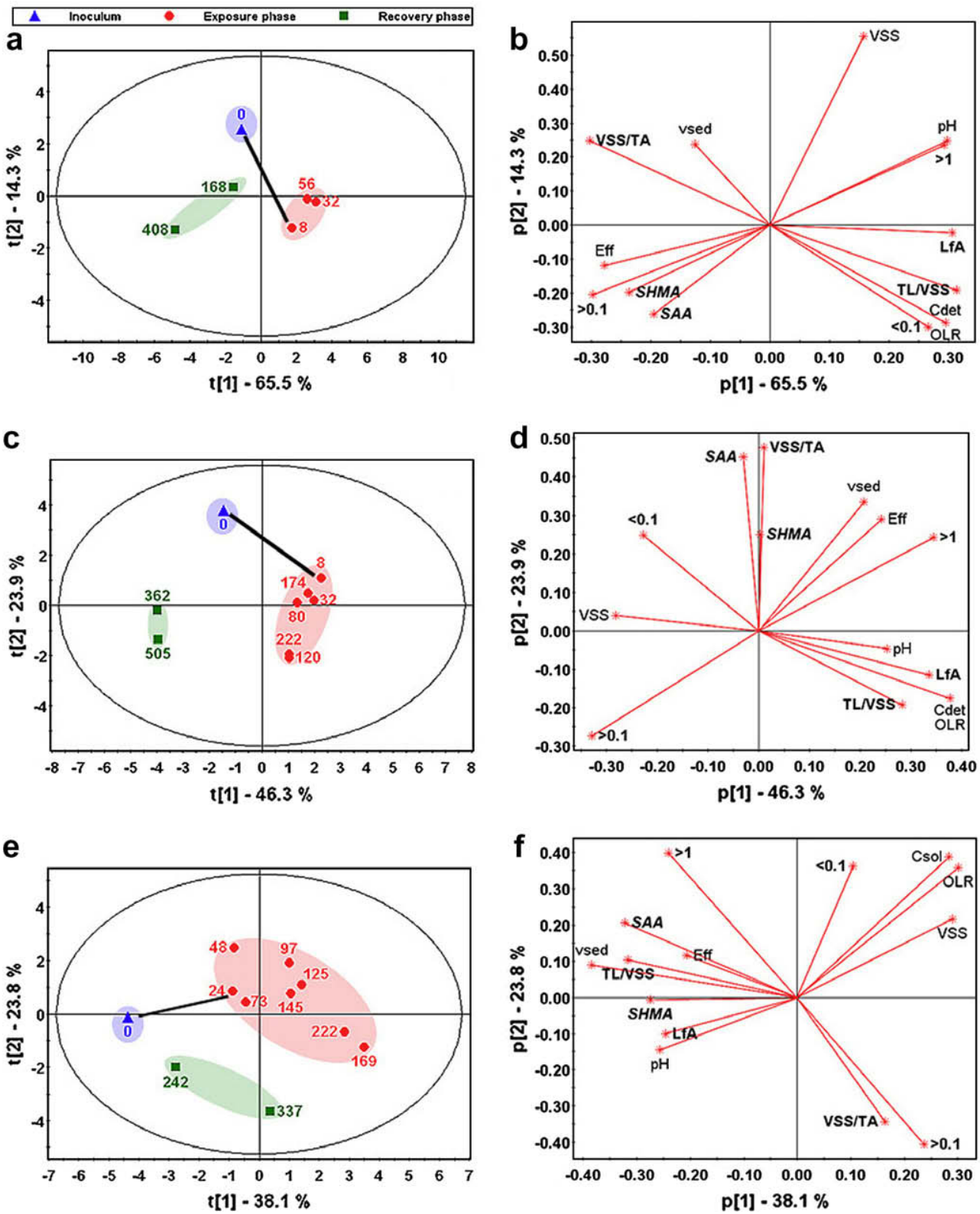

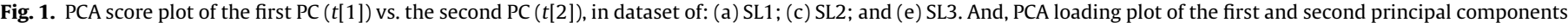
( $p[1]$ vs. $p[2])$, from dataset of: (b) SL1; (d) SL2; and (f) SL3.

difficult to obtain. The use of image analysis techniques, previously described by Amaral (2003) and Costa et al. (2007), provides quantitative information about the dynamic evolution of the granules morphology at macro and microstructures levels. The use of PCA illustrates the usefulness of monitoring the granules morphology to detect possible toxic contamination and future operational problems. The early detection of these problems is essential to attain timely control of the process before it evaluates to an irreversible problem. In this work was visible that morphological changes occurred before reactors performance deterioration, proving the sensitivity of the proposed parameters to detect the toxic contaminations.

PCA provides information on the most meaningful parameters, which describes a whole dataset affording data reduction with minimum loss of original information (Helena et al., 2000). It was applied previously to classify and predict ash and char content from near infrared spectra collected on different types of biomass (Labbé et al., 2008). In this work, a new latent variable, $t[1]$,
Table 4

Loadings/weights of the variables in datasets associated to the PC1

\begin{tabular}{lllll}
\hline Variable & SL1 & SL2 & SL3 & Notes \\
\hline OLR & 0.295 & 0.377 & 0.300 & Controlled variable \\
Cdet & 0.295 & 0.377 & - & Controlled variable \\
Csol & - & - & 0.283 & Controlled variable \\
Eff & -0.278 & 0.241 & -0.206 & \\
pH & 0.297 & 0.253 & -0.256 & \\
VSS & 0.158 & -0.280 & 0.290 & \\
$<0.1$ & 0.265 & -0.227 & 0.104 & Morphological variable \\
$>0.1$ & -0.297 & $-\mathbf{0 . 3 2 9}$ & 0.236 & Morphological variable \\
$>1$ & 0.293 & $\mathbf{0 . 3 4 5}$ & -0.241 & Morphological variable \\
SAA & -0.194 & -0.030 & $-\mathbf{0 . 3 2 1}$ & \\
SHMA & -0.236 & 0.003 & -0.275 & \\
LfA & $\mathbf{0 . 3 0 6}$ & $\mathbf{0 . 3 3 6}$ & -0.246 & Morphological variable \\
VSS/TA & $-\mathbf{0 . 3 0 2}$ & 0.009 & 0.164 & Morphological variable \\
TL/VSS & $\mathbf{0 . 3 1 3}$ & 0.283 & $\mathbf{- 0 . 3 1 6}$ & Morphological variable \\
vsed & -0.126 & 0.207 & $-\mathbf{0 . 3 8 4}$ & \\
\hline
\end{tabular}



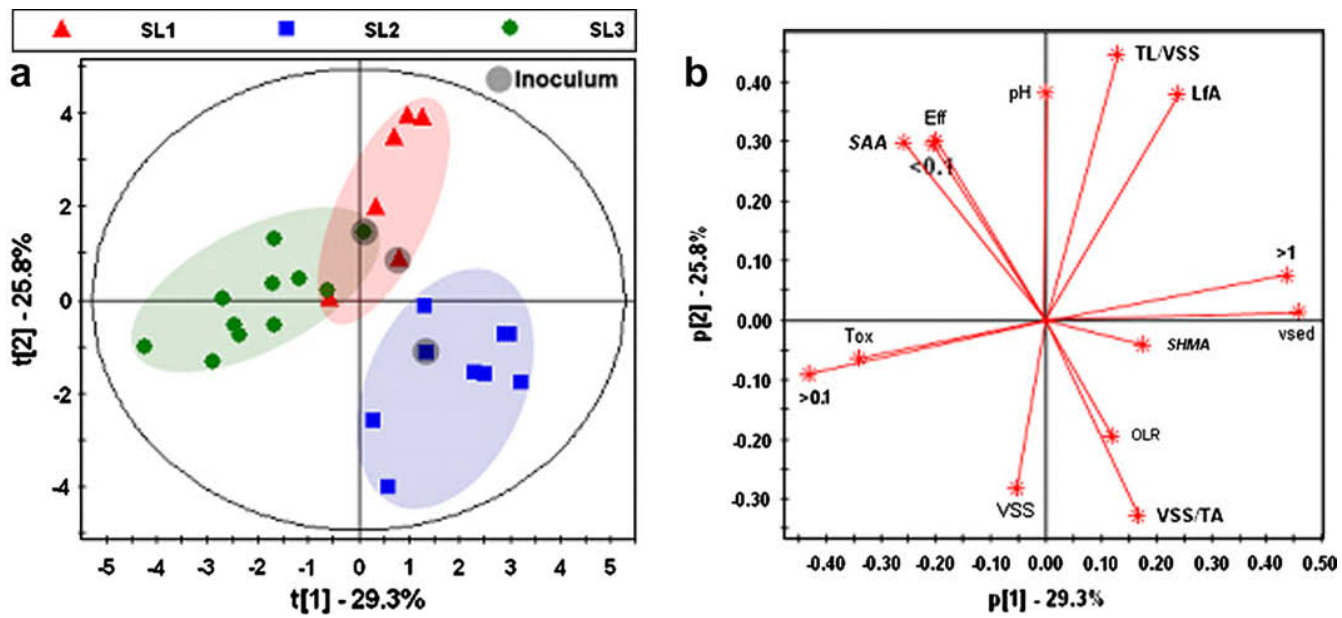

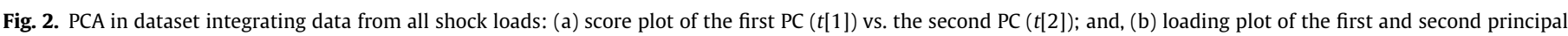
components ( $p[1]$ vs. $p[2])$.

was defined that includes a weighted sum of performance, physiological and morphological information. This new variable can be used as a warning indicator of operational problems during toxic shock load disturbances. The variable $t[1]$ was calculated for the inoculum and the first sample of exposure phase and the corresponding \% of variation was $262 \%, 254 \%$ and $80 \%$, respectively, in SL1, SL2 and SL3. This result evidenced the high sensitivity of the latent variable to recognize deviations of the normal process operation.

Analyzing the loadings/weights associated with the new latent variable $t[1]$, it is possible to distinguish the variables that most influence the early detection of reactors contaminations. The morphological parameters emerge due to its high loadings in all datasets (Table 4). These results confirm that quantitative morphological parameters should be considered in monitoring and control of high-rate anaerobic reactors, especially those based on granular sludge. Similar conclusions were obtained when high-rate anaerobic reactors were subjected to organic loading disturbances (Costa et al., 2008).

\subsection{Differentiate the shock loads}

A PCA in a dataset integrating all available information was performed in order to highlight differences between the shock loads. Watching at Fig. 2a three clusters, one for each shock load, can be perfectly distinguished. The cluster encompassing the SL2 samples is isolated from the others. Effectively, SL2 caused the most negative effects to the anaerobic granular sludge, since it was the only one where the COD removal efficiency decreased significantly during the exposure phase.

The score and loading plots of PC1 and PC2, t[1] vs. $t[2]$ and $p[1]$ vs. $p$ [2] (Fig. 2), show the variables with higher influence in each shock load. SL1 was characterized by an increase in TL/VSS and LfA. The decrease of Efficiency (Eff) and SAA and increase of granules density describe SL2. Regarding to SL3 it was categorized mostly by the granules $D_{\text {eq }}$ ranges $>1$ and $>0.1$, sign of granules fragmentation.

Searching for possible correlations between variables, it is possible to observe a high positive correlation between the total filaments (TL/VSS) and the dynamic of filaments per area of aggregates (LfA) (Fig. 2b). This was already postulated by Costa et al. (2008), suggesting that the granules microstructure stabilization, by locking the filaments inside the aggregates, play a more important role in the maintenance of a high efficiency than granules macrostructure/size stabilization.
During the shock loads was observed that LfA increased 3, 5 , and 2 days before effluent volatile suspended solids, respectively in SL1, SL2, and SL3. It was hypothesized that LfA could be an early-warning indicator of washout events (Amaral et al., 2004; Costa et al., 2007, 2008). In Fig. 2b is visible that LfA and VSS are inversely proportional, enhancing the hypothesis that LfA increases before VSS, decreasing afterwards when VSS increases.

The detergent caused specific acetoclastic activity inhibition and COD removal efficiency deterioration only in SL2 (high concentration and exposure time). Regarding to solvent, a decrease of COD removal efficiency occurred only when the biomass was saturated, more than $200 \mathrm{~h}$ after the shock load began. Anaerobic biomass can acclimate to toxic compounds and recover from inhibition as long as the toxicant concentration is below a threshold level (Tepe et al., 2006). Therefore, strategies that make the contaminants concentration entering in the reactor lower, for example increasing the dilution rate, should be implemented after toxic state recognition to overcome/minimize the possible problematic contamination of the process.

\section{Conclusions}

The PCA allowed the visualization of the main effects caused by the toxics, by clustering the samples according to its operational phase, exposure or recovery.

In SL1 (1.6 mg detergent $\left.\mathrm{L}^{-1}\right)$ and SL3 (40 mg solvent $\left.\mathrm{L}^{-1}\right)$, changes in micro and macrostructure of the granules were observed, although the reactors performance was virtually unaffected. In SL2 (300 $\mathrm{mg}_{\text {detergent }} \mathrm{L}^{-1}$ ) the morphological changes were detected in the morphological parameters before the detection of a decrease in the reactor efficiency. The new latent variable $t[1]$, defined as an weighted sum of all variables included in the dataset, showed a variation of $262 \%, 254 \%$ and $80 \%$, respectively, in SL1, SL2 and SL3. The high loadings/weights of the morphological parameters enhanced the usefulness of monitoring the solid phase of the anaerobic digestion process (biomass), in order to achieve an effective and timely control. It was showed that PCA allowed the differentiation of the several shock loads.

\section{Acknowledgements}

We grateful acknowledge the financial support to J.C. Costa through the Grant SFRH/BD/13317/2003 and the Project POCTI/ AMB/60141/2001 from the Fundação para a Ciência e a Tecnologia (Portugal). 


\section{References}

Abouelwafa, R., Amir, S., Souabi, S., Winterton, P., Ndira, V., Revel, J.-C., Hafidi, M., 2008. The fulvic acid fraction as it changes in the mature phase of vegetable oilmill sludge and domestic waste composting. Bioresource Technology 99, 61126118.

Amaral, A.L., 2003. Image Analysis in Biotechnological Processes: Application to Wastewater Treatment. Ph.D. Thesis, University of Minho, Portugal. <http:// hdl.handle.net/1822/4506>.

Amaral, A.L., Pereira, M.A., da Motta, M., Pons, M.-N., Mota, M., Ferreira, E.C., Alves, M.M., 2004. Development of image analysis techniques as a tool to detect and quantify morphological changes in anaerobic sludge: II. Application to a granule deterioration process triggered by contact with oleic acid. Biotechnology and Bioengineering 87 (2), 194-199.

Costa, J.C., Abreu, A.A., Ferreira, E.C., Alves, M.M., 2007. Quantitative image analysis as a diagnostic tool for monitoring structural changes of anaerobic granular sludge during detergent shock loads. Biotechnology and Bioengineering 98 (1), 60-68.

Costa, J.C., Moita, I., Abreu, A.A., Ferreira, E.C., Alves, M.M., 2008. Advanced monitoring of high rate anaerobic reactors through quantitative image analysis of granular sludge and multivariate statistical analysis. Biotechnology and Bioengineering. doi:10.1002/bit.22071.

Einax, J.W., Zwanziger, H.W., Geiss, S., 1997. Chemometrics in Environmental Analysis. VCH, Weinheim.

Enright, A.-M., McHugh, S., Collins, G., O'Flaherty, V., 2005. Low-temperature anaerobic biological treatment of solvent-containing pharmaceutical wastewater. Water Research 39 (19), 4587-4596.

Fuentes, A., Lloréns, M., Saéz, J., Aguilar, M.I., Ortuño, J.F., Meseguer, V.F., 2008 Comparative study of six different sludges by sequential speciation of heavy metals. Bioresource Technology 99, 517-525.

Garcia, C., Molina, F., Roca, E., Lema, J.M., 2007. Fuzzy-based control of an anerobic reactor treating wastewaters containing ethanol and carbohydrates. Industrial \& Engineering Chemistry Research 46 (21), 6707-6715.

Gavala, H.N., Ahring, B.K., 2002. Inhibition of the anaerobic digestion process by linear alkylbenzene sulfonates. Biodegradation 13, 201-209.

Gil, M.V., Calvo, L.F., Blanco, D., Sánchez, M.E., 2008. Assessing the agronomic and environmental effects of the application of cattle manure compost on soil by multivariate methods. Bioresource Technology 99, 5763-5772.

Helena, B., Pardo, R., Vega, M., Barrado, E., Fernandez, J.M., Fernandez, L., 2000. Temporal evolution of groundwater composition in an alluvial aquifer (Pisuerga
River, Spain) by principal component analysis. Water Research 34 (3), 807816.

Labbé, N., Lee, S.-H., Cho, H.-W., Jeong, M.-K., André, N., 2008. Enhanced discrimination and calibration of biomass NIR spectral data using non-linear kernel methods. Bioresource Technology 99, 8445-8452.

Lardon, L., Puñal, A., Martinez, J.A., Steyer, J.P., 2005. Modular expert system for the diagnosis of operating conditions of industrial anaerobic digestion plants. Water Science \& Technology 52 (1-2), 427-433.

Lee, D.S., Vanrolleghem, P.A., 2004. Adaptive consensus principal component analysis for on-line batch process monitoring. Environmental Monitoring and Assessment 92, 119-135.

Lee, D.S., Lee, M.W., Woo, S.H., Kim, Y.-J., Park, J.M., 2006. Multivariate online monitoring of a full-scale biological anaerobic filter process using kernel-based algorithms. Industrial \& Engineering Chemistry Research 45, 4335-4344.

Lee, J.M., Yoo, C.K., Choi, S.W., Vanrolleghem, P.A., Lee, I.B., 2004. Nonlinear process monitoring using kernel principal component analysis. Chemical Engineering Science 59, 223-234.

Lettinga, G., 1995. Anaerobic digestion and wastewater treatment systems. Antoine van Leeuwenhoek 67, 3-28.

Li, W., Yue, H., Valle-Cervantes, S., Qin, S.J., 2000. Recursive PCA for adaptive process monitoring. Journal of Process Control 10, 471-486.

MacGregor, J.F., Koutodi, M., 1995. Statistical process control of multivariate process. Control Engineering Practice 3 (3), 403-414

Rosen, C.A., 2001. Chemometric Approach To Process Monitoring And Control With Applications To Wastewater Treatment Operation. Ph.D. Thesis, Lund University, Sweden.

Tepe, N., Shimko, L.A., Duran, M., 2006. Toxic effects of thiol-reactive compounds on anaerobic biomass. Bioresource Technology 97 (4), 592-598.

Van Lier, J.B., Tilche, A., Ahring, B.K., Macarie, H., Moletta, R., Dohanyos, M., Hulshoff Pol, L.W., Lens, P., Verstraete, W., 2001. New perspectives in anaerobic digestion. Water Science and Technology 43 (1), 1-18.

Wise, B.M., Gallagher, N.B., 1996. The process chemometrics approach to process monitoring and fault detection. Journal of Process Control 6 (6), 329-348.

Zehnder, A.J.B., Huser, B.A., Brock, T.D., Wuhrmann, K., 1980. Characterization of an acetate-decarboxylating, non-hydrogen-oxidizing methane bacterium. Archives of Microbiology 124 (1), 1-11.

Zbytniewski, R., Buszewski, B., 2005. Characterization of natural organic matter (NOM) derived from sewage sludge compost. Part 2: multivariate techniques in the study of compost maturation. Bioresource Technology $96,479-484$. 